\title{
Characteristics of Samaria-Doped Ceria Prepared by Pechini Method
}

\author{
A. ARABACI* AND Ö. SERIN \\ Istanbul University, Faculty of Engineering, Department of Metallurgical Engineering, \\ Avcilar 34320, Istanbul, Turkey
}

\begin{abstract}
$\mathrm{CeO}_{2}$ ceramics doped with 20 mol.\% samarium (SDC-20) were prepared through the Pechini process. The samples were calcined at 400,700 and $1000^{\circ} \mathrm{C}$. The sintering behavior of the calcined SDC-20 powders was also investigated at $1400^{\circ} \mathrm{C}$ for $6 \mathrm{~h}$. Microstructural and physical properties of SDC-20 samples were characterized with $\mathrm{X}$-ray diffraction, scanning electron microscopy, thermogravimetry and impedance analysis methods. The results of the thermogravimetry/differential thermal analysis and X-ray diffraction indicated that a single-phase fluorite structure formed at a relatively low calcination temperature of $400{ }^{\circ} \mathrm{C}$. It is understood from the measured ionic conductivity values that the pellet formed from the SDC-20 samples calcined at $1000^{\circ} \mathrm{C}$ had lower resistance of grain-boundary than those of the pellets formed from the SDC-20 samples calcined at 400 and $700{ }^{\circ} \mathrm{C}$. The maximum ionic conductivity was measured as $1.95 \times 10^{-2} \mathrm{~S} \mathrm{~cm}^{-1}$ at $800^{\circ} \mathrm{C}$ for the sintered SDC-20 pellet obtained from SDC-20 powders calcined at $1000^{\circ} \mathrm{C}$.
\end{abstract}

DOI: 10.12693/APhysPolA.128.B-118

PACS: 88.30.pn

\section{Introduction}

Solid oxide fuel cell (SOFC) has a big potential as an alternative energy system in the future. It has many advantages such as high efficiency, low cost in maintenance, and environmentally friendly. It has high large fuel flexibility such as methane, hydrogen, or carbon monoxide. In general, traditional SOFC systems are used yttriastabilized zirconia (YSZ) as electrolyte materials. But, it must operate at temperatures between 800 and $1000^{\circ} \mathrm{C}$ to achieve acceptable efficiencies $[1,2]$. However, operation at such a high temperature causes some problems, including interfacial reaction between the components, mechanical and thermal degradation, thermal expansion, mismatch, and high cost materials. Therefore, it is necessary to lower the operating temperature $\left(600-800^{\circ} \mathrm{C}\right)$ of the SOFCs.

In recent years, doped ceria electrolytes especially, rare earth doped ceria are a possible candidate as an electrolyte materials for intermediate temperature $(600$ $800{ }^{\circ} \mathrm{C}$ ) SOFCs due to their higher ionic conductivity and good thermodynamic stability. Among doped ceria electrolytes such as the trivalent rare-earth doped ceria, the highest conductivities are observed for $\mathrm{Ce}_{1-x} \mathrm{Sm}_{x} \mathrm{O}_{2-x / 2}$ and $\mathrm{Ce}_{1-x} \mathrm{Gd}_{x} \mathrm{O}_{2-x / 2}[3,4]$. Therefore, the researchers are focused on the ceria based on electrolytes. There are several methods for preparing samarium doped ceria such as combustion [5], sol-gel [6], mechanochemical [7], hydrothermal [8], microemulsion [9] and glycinenitrate [10]. Preparation processes play an important role on the mean sizes and morphologies of the ceria

\footnotetext{
*corresponding author; e-mail: aliye@istanbul.edu.tr
}

nanoparticles. Mean sizes and morphologies of nanoparticles are essential factors in controlling the final ceramic microstructure [11].

In present study, ceria ceramics doped with Sm (20 mol.\%) were prepared by Pechini method. This technique is a simple process in comparison to the other methods. It requires simple equipment and it is not a tedious method. The precursor particles prepared by the Pechini method were calcined at temperatures between 400 and $1000^{\circ} \mathrm{C}$ for $2 \mathrm{~h}$. Effects of calcination temperatures of samaria-doped ceria powders on the properties of sintered bodies and ionic conductivities were investigated. Moreover, the thermal decomposition behaviours of the products were also examined by using thermal gravimetric analysis technique (Fig. 1).

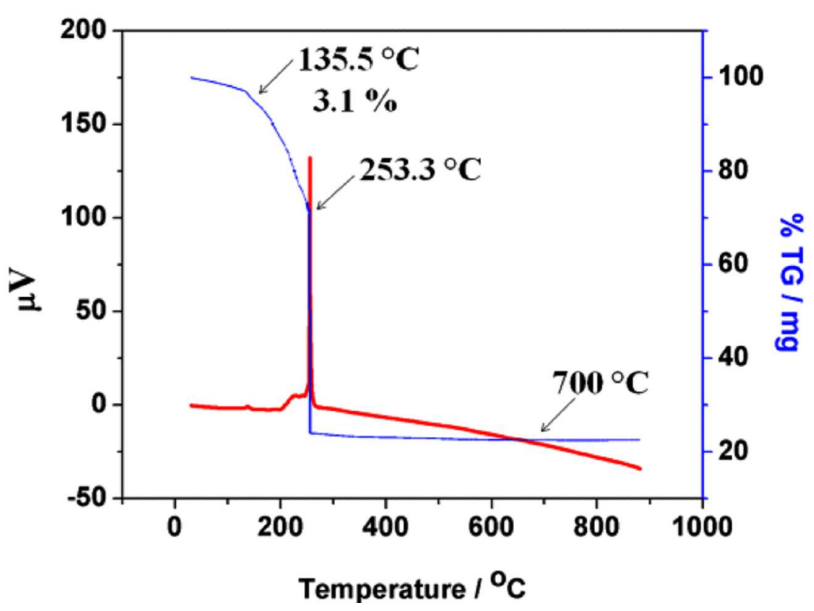

Fig. 1. TG-DTA curves of thermal decomposition of SDC-20 precursors at a heating rate of $10^{\circ} \mathrm{C} \mathrm{min}^{-1}$ in air. 


\section{Experimental}

High purity cerium nitrate $\left(\mathrm{Ce}\left(\mathrm{NO}_{3}\right)_{3} \cdot 6 \mathrm{H}_{2} \mathrm{O}\right)$, samarium nitrate $\left(\mathrm{Sm}\left(\mathrm{NO}_{3}\right)_{3} \cdot 6 \mathrm{H}_{2} \mathrm{O}\right.$ were used as the sources of $\mathrm{Ce}$ and $\mathrm{Sm}$ components, and ethyleneglycol (R.P. Normopur), citric acid (BoehringerIngelheim) were selected for the polymerization treatment. More details on the Pechini method are reported in our earlier work [12]. The gel formed precursor obtained by the Pechini method was dried at $110^{\circ} \mathrm{C}$ for $24 \mathrm{~h}$. The thermal behaviour of the dried SDC-20 precursors was carried out with SII Exstar 6000 TG/DTA 6300 from 40 to $850^{\circ} \mathrm{C}$ at a heating rate of $10^{\circ} \mathrm{C} \mathrm{min}{ }^{-1}$ in a flow of air. The results of the differential thermal analysis (DTA) and thermogravimetric analysis (TGA) as a function of temperature were plotted (Fig. 1). X-ray diffraction (XRD) technique was used to determine the crystal structure and phase. The conversion of the so-prepared amorphous precursors into crystalline samarium-doped $\mathrm{CeO}_{2}$ was achieved by heating the dried precursor particles at a rate between $5^{\circ} \mathrm{C} \min ^{-1}$ to either 400,700 and $1000{ }^{\circ} \mathrm{C}$, and keeping them at these temperatures for $2 \mathrm{~h}$. The X-ray spectra of samarium-doped ceria particles were obtained over the $2 \theta$ range of $10-90^{\circ}$ by using Rigaku $\mathrm{D} / \max -2200$ PC X-ray diffractometer with $\mathrm{Cu} K_{\alpha_{1}}(\lambda=0.15406 \mathrm{~nm})$ radiation.

The average crystallite sizes of the calcined samples were calculated by using the well-known Scherrer equation. Subsequently, the calcined powders were pressed to disk shaped pellets with an uniaxial hydraulic, followed by a cold-isostatic press at $200 \mathrm{MPa}$. Obtained pellets were sintered at $1400^{\circ} \mathrm{C}$ for $6 \mathrm{~h}$ with a heating rate of $5{ }^{\circ} \mathrm{C} \mathrm{min}^{-1}$. The sample densities were measured by the Archimedes method after sintering (water was used as solvent (water at $25^{\circ} \mathrm{C} 0.997 \mathrm{~g} \mathrm{~cm}^{-1}$ )) The morphological characteristics of the calcined powders and sintered pellets were investigated using scanning electron microscopy (SEM) (FEI-QUANTA FEG 450). Impedance measurements (electrochemical impedance spectroscopy (EIS)) were taken by using SOLARTRON $1260 \mathrm{FRA}$ and 1296 interface at temperature ranges between 300 and $800{ }^{\circ} \mathrm{C}$ in air atmosphere. Before performing the impedance measurements, $\mathrm{Ag}$ paste was brushed onto both sides of the as-sintered disk-shaped pellets to serve as the electrode. The pellets were then co-fired at $800{ }^{\circ} \mathrm{C}$ for $30 \mathrm{~min}^{-1}$. $\mathrm{Ag}$ wires $(99.9 \%$ pure) were attached to the cell using Ag adhesive paste to perform ionic conductivity measurements. For impedance measurement at different temperatures, each sample was individually heated in a quartz reactor which was placed inside a small split tube furnace. The thermocouple was kept in close proximity to the sample to minimize the temperature measurement errors.

\section{Results and discussion}

To further evaluate the composition of the dried SDC20 precursors $\left(\right.$ at $110^{\circ} \mathrm{C}$ ) and to elucidate their transformation to crystalline $\mathrm{Ce}_{0.8} \mathrm{Sm}_{0.2} \mathrm{O}_{1.90}$, extensive TGA analyses were carried out. The samples were heated from room temperature to $850^{\circ} \mathrm{C}$ at a heating rate of $10^{\circ} \mathrm{C} /$ min under air atmosphere. Figure 1 displays the DTA-TG results of the dried gels. As seen in Fig. 1, weight loss occurred in three steps. In the first step, minor weight-loss of $3.1 \%$ between 40 and $\approx 135^{\circ} \mathrm{C}$ which is related to the loss of adsorbed water. In the second step, a weight loss of $25.5 \%$ occurred in the temperature range of $\approx 135-253^{\circ} \mathrm{C}$. The next step which is shown in Fig. 1 at $\approx 253^{\circ} \mathrm{C}$, an abrupt weight loss of about $47.4 \%$ is accompanied by a strong exothermic DTA peak, which indicates the removal of the combustion of organic materials and the thermal decomposition of the dried gels. No apparent mass loss occurs at temperatures $T>400^{\circ} \mathrm{C}$, suggesting the formation of crystalline $\mathrm{Ce}_{0.8} \mathrm{Sm}_{0.2} \mathrm{O}_{1.90}$ as a decomposed product. The XRD results also verify this finding.

To confirm the complete dissolution of dopants in ceria, phase analysis was performed using X-ray diffraction (XRD) (Fig. 2). According to the results of DTA/TG, crystallization of the powder occurred by calcination at $>400^{\circ} \mathrm{C}$, and almost all the characteristic diffraction peaks corresponding to the fluorite structure of $\mathrm{CeO}_{2}$ (JCPDS Card No. 34-0394). It is clearly seen that the reflection peaks become sharper and narrower with increasing calcination temperature, indicating that the crystal sizes increases and the crystallinity of the powders become better defined during the calcination process. After heating at $1000^{\circ} \mathrm{C}$, the peaks' widths become very narrow and intense, indicating a rapid increase in the growth of the crystallite size.

Crystallite sizes of the SDC-20 powders were found as 11.7, 23 and $35.2 \mathrm{~nm}$ for the calcination temperatures of $400,700,1000^{\circ} \mathrm{C}$, respectively. No crystalline phases corresponding to $\mathrm{Sm}_{2} \mathrm{O}_{3}$ were found in the Sm-doped ceria for each calcination temperature. The results indicate that the dopant ion was fully substituted in the $\mathrm{CeO}_{2}$ lattice.

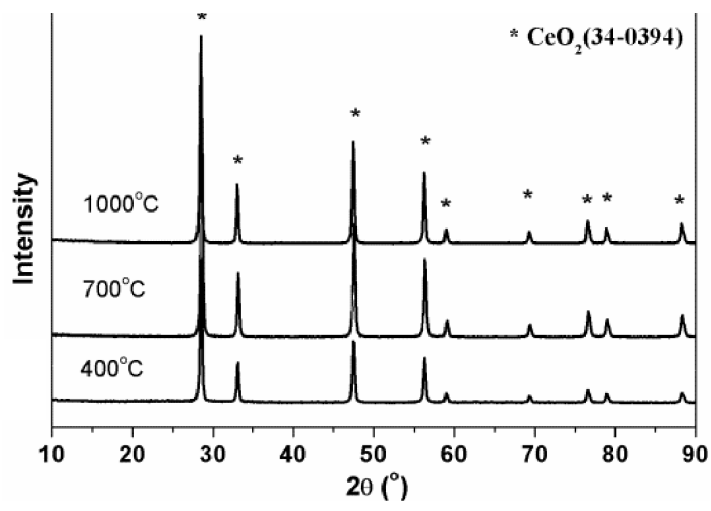

Fig. 2. XRD patterns of SDC-20 powders calcined at different calcination temperatures in air for $2 \mathrm{~h}$.

Figure 3 shows the SEM images of the surface of the sintered SDC-20 pellets calcined at different calcination temperatures. It is very clear that the samples in Fig. 3a 
and $\mathrm{b}$ are nearly dense with a few pores. However, the microstructure of the sintered SDC-20 pellet calcined at $1000^{\circ} \mathrm{C}$ was observed to be fully dense (Fig. 3c). The pellets formed from the SDC particles calcined at 400 and $700^{\circ} \mathrm{C}$ had similar grain sizes 0.70 and $0.74 \mu \mathrm{m}$, respectively. The sample formed from the SDC particles calcined at a temperature of $1000^{\circ} \mathrm{C}$ had a larger grain size of $1.12 \mu \mathrm{m}$. Similar findings were observed for the relative density of the SDC-20 samples. The calculated relative densities for the sintered pellet formed from the SDC-20 particles calcined at $400,700,1000^{\circ} \mathrm{C}$ are $94.7,95$ and $96.5 \%$ of the theoretical value, respectively. These results remarked that the calcination temperatures of the SDC-20 particles strongly affected the characteristics of the pellets. The relative densities of the pellets increased with the increasing calcination temperatures of the SDC-20 particles.

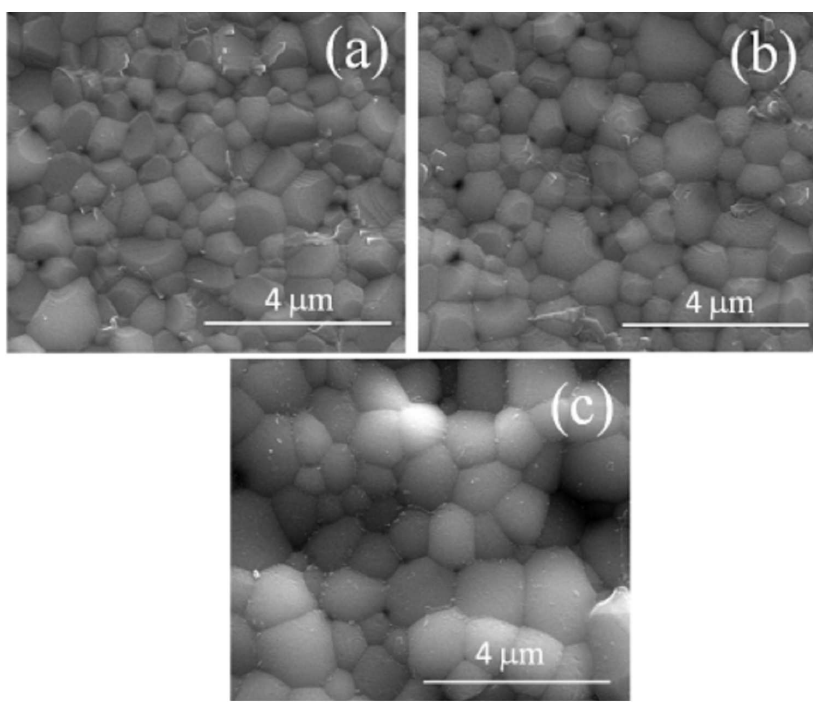

Fig. 3. SEM images of SDC-20 pellets formed from the SDC powders calcined at various temperatures; (a) $400{ }^{\circ} \mathrm{C}$, (b) $700{ }^{\circ} \mathrm{C}, \quad$ (c) $1000{ }^{\circ} \mathrm{C}(30000 \times$ for all samples).

The impedance spectrum of an ionic conductor contains contributions from the grain interior (the first arc), the grain boundary (the second arcs), and the electrode-electrolyte interface, which can be simplified by three arcs. Depending on the nature of the sample and conditions of the experiment, all of these arcs cannot be observed $[13,14]$. The complex impedance spectra plots, which were constructed for operating temperatures of $300^{\circ} \mathrm{C}$ and $400{ }^{\circ} \mathrm{C}$ in air, for the SDC-20 samples sintered at $1400^{\circ} \mathrm{C}$ for $6 \mathrm{~h}$ are shown in Fig. 4. In Fig. 4a, two semicircular arcs, which denote the grain interior and grain boundary, are discernible. The first arc (half-circle) in left side means resistivity of grain interior. The second arcs in right side represent resistivity of grain-boundary. However, with increasing operating temperature $\left(400^{\circ} \mathrm{C}\right)$ in Fig. 4b-d the first semicircle (the high-frequency arc) disappears and only the grain boundary and electrode arcs are visible. The same trend was observed for all ex- amined samples calcined at various temperatures. At elevated operating temperatures in the approximate range of $700-800^{\circ} \mathrm{C}$, a single arc, which represents the electrode, was observed. In present study, as can be seen from Fig. 4, the grain-boundary resistivity was affected by calcination temperatures of SDC-20 particles. It can be observed, from the SEM images (see Fig. 3), that the grain-boundary resistivity decreased with increase of grain size from 0.70 to $1.12 \mu \mathrm{m}$. The SDC-20 pellets obtained from particles calcined between 400 and $700^{\circ} \mathrm{C}$ had small grain size which shows a fairly large grain-boundary resistivity. However, the SDC-20 pellet obtained from particles calcined at $1000^{\circ} \mathrm{C}$ had the biggest grain size as $1.12 \mu \mathrm{m}$, thus smallest percentage of grain-boundary region which result in the smallest grainboundary resistivity.

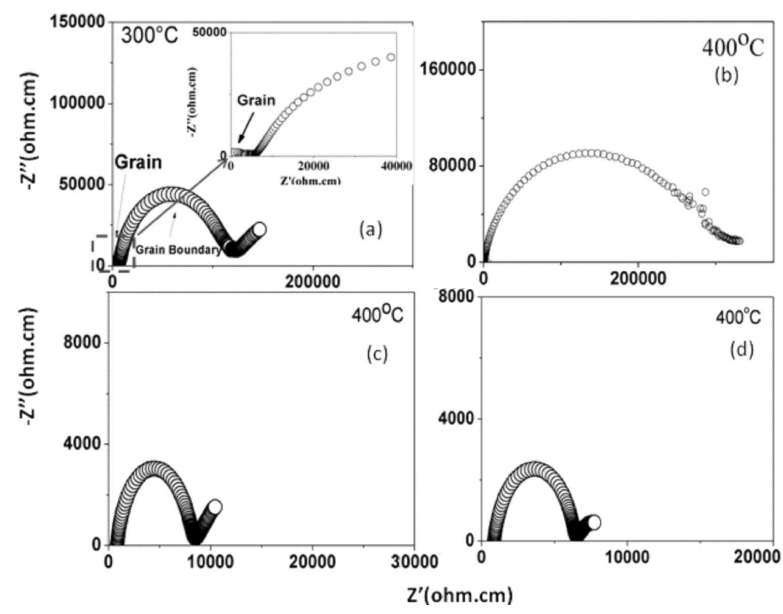

Fig. 4. (a) Complex impedance spectra measured at $300^{\circ} \mathrm{C}$ for SDC-20 powders calcined at $700^{\circ} \mathrm{C}$, (b), (c) and (d) complex impedance spectra measured at $400^{\circ} \mathrm{C}$ for SDC-20 pellets formed from the SDC-20 powders calcined at $400{ }^{\circ} \mathrm{C}, 700^{\circ} \mathrm{C}, 1000^{\circ} \mathrm{C}$, respectively.

These pellets had high conductivity due to low resistance of grain-boundary of the pellet. The total ionic conductivity of the samples were calculated according to the Ohm law by using the total impedance data and dimensions (thickness and area) of the pellets. The maximum ionic conductivity was measured as $1.95 \times 10^{-2} \mathrm{~S} \mathrm{~cm}^{-1}$ at operating temperature of $800^{\circ} \mathrm{C}$ for the SDC-20 pellet obtained from particles calcined at $1000^{\circ} \mathrm{C}$.

\section{Conclusion}

Samaria-doped ceria particles were prepared by the Pechini method. After calcinations at temperatures between 400 and $1000^{\circ} \mathrm{C}$, the $\mathrm{XRD}$ results indicated that a single-phase fluorite structure was formed. The calcination temperatures of the SDC-20 particles strongly affected the characteristics of the pellets sintered at a temperature of $1400^{\circ} \mathrm{C}$ for $6 \mathrm{~h}$. The pellets formed from 
the SDC particles calcined at 400 and $700{ }^{\circ} \mathrm{C}$ had similar grain sizes around $0.70-0.74 \mu \mathrm{m}$. However, pellet formed from the SDC particles calcined at $1000^{\circ} \mathrm{C}$ had large grain size of $1.12 \mu \mathrm{m}$. The ionic conductivity results showed that the pellet formed from the SDC particles calcined at $1000^{\circ} \mathrm{C}$ had lower resistance of grain-boundary than those of the pellets formed from the SDC particles calcined at 400 and $700{ }^{\circ} \mathrm{C}$. Thus, the pellet formed from the SDC particles calcined at a temperature of $1000^{\circ} \mathrm{C}$ had highest conductivity value at all measuring temperatures. According to the EIS results, the ionic conductivity value of the sintered SDC-20 pellet obtained from SDC-20 powders calcined at $1000^{\circ} \mathrm{C}$ was calculated as $1.95 \times 10^{-2} \mathrm{~S} \mathrm{~cm}^{-1}$ at $800^{\circ} \mathrm{C}$.

\section{Acknowledgments}

This work was financially supported by the Research Fund of Istanbul University with the project numbers: 42193 .

\section{References}

[1] J.P.P. Huijsmans, F.P.F. van Berkel, G.M. Christie, J. Power Sources 71, 107 (1998).

[2] H. Yoshida, K. Miura, T. Fukui, S. Ohara, T. Inagaki, J. Power Sources 106, 136 (2002).
[3] H. Yahiro, Y. Eguchi, K. Eguchi, H. Arai, J. Appl. Electrochem. 18, 527 (1988).

[4] B.C.H. Steele, in: High Conductivity Solid Ionic Conductors - Recent Trends and Applications, Ed. T. Takahashi, World Sci., London 1989, p. 402.

[5] M.M.A. Sekar, S.S. Manoharan, K.C. Patil, J. Mater. Sci. Lett. 9, 1205 (1990).

[6] G.S. Wu, T. Xie, X.Y. Yuan, B.C. Cheng, L.D. Zhang, Mater. Res. Bull. 39, 1023 (2004).

[7] Y.X. Li, W.F. Chen, X.Z. Zhou, Mater. Lett. 59, 48 (2005).

[8] Y.C. Zhou, M.N. Rahman, J. Mater. Res. 8, 1680 (1993).

[9] T. Matsui, K. Fujiwara, K. Machida, G. Adachi, T. Sakata, H. Mori, Chem. Mater. 9, 2197 (1997).

[10] C.R. Xia, M.L. Liu, Solid State Ionics 152, 423 (2002).

[11] H.C. Jang, D.S. Jung, J.H. Kim, Y.C. Kang, Y.H. Cho, J.H. Lee, Ceram. Int. 36, 465 (2010).

[12] A. Arabaci, M.F. Öksüzömer, Ceram. Int. 38, 6509 (2012).

[13] T.S. Zhang, J. Ma, Y.Z. Chen, L.H. Luo, L.B. Kong, S.H. Chan, Solid State Ionics 177, 1227 (2006).

[14] D.Y. Wang, A.S. Nowick, J. Solid State Chem. 35, 325 (1980). 